\title{
ATENCIÓN MÉDICA, ADHERENCIA TERAPÉUTICA AL TRATAMIENTO ANTIRRETROVIRAL Y DISCRIMINACIÓN.
}

\author{
Algunas problemáticas en la atención a personas que viven con VIH-sida, \\ desde una perspectiva antropológica
}

Rubén Muñoz Martínez

rubmuma@hotmail.com

(CIESAS-Sureste)

\section{RESUMEN}

En este texto se abordan algunas de las problemáticas en el acceso, por parte de los usuarios, a los cuidados en prevención/atención/control del VIH-sida del consultorio médico del Servicio de Atención Integral (SAI), perteneciente a una clínica de la Secretaría de Salud en San Cristóbal de Las Casas (Chiapas). En particular aquellas vinculadas con la discriminación, y concretamente la relacionada con la orientación sexual y el itinerario socio/cultural del usuario del SAI, en la relación médico-paciente-institución. Para ello analizo las representaciones sociales de los médicos del consultorio con respecto a las prácticas sexuales (y preventivas de VIH-sida) y a los modelos explicativos del trinomio salud/enfermedad/atención de los sujetos y colectivos destinatarios, y las praxis de cuidados en dicho consultorio.

Palabras clave: VIH-sida, discriminación, adherencia a la consulta.

\section{HEALTH CARE, ADHERENCE TO ANTIRETROVIRAL THERAPY AND DISCRIMINATION.}

Some issues in healh care for people living with

HIV-aids, from an anthropological perspective

\begin{abstract}
This text addresses some problems regarding access by users to HIV-AIDS prevention/care/control services at the medical office of Servicio de Atención Integral (SAI by its acronym in Spanish), pertaining to a Mexican Health Department clinic in San Cristóbal de Las Casas, Chiapas. It specifically focuses on discrimination-related issues, concretely regarding the user's sexual orientation and socio-cultural trajectory through SAI, as well as the doctor-patient-institution relationship. The representations of the clinic's doctors regarding sexual and HIV-AIDS preventive practices as well as the explicatory models of the health/disease/care triad of the subjects and collective recipients, and the clinic's health care praxis are analyzed.
\end{abstract}

Key words: HIV-AIDS, discrimination, treatment adherence. 


\section{INTRODUCCIÓN}

Los resultados de la investigación ${ }^{1}$ y las discusiones que a partir de ellos se plantean aquí tienen por objetivo dilucidar algunas de las problemáticas en el acceso, por parte de los usuarios, a los cuidados en prevención/atención/control de VIH-sida del consultorio médico del Servicio de Atención Integral $(\mathrm{SAI})^{2}$ en la clínica I, ${ }^{3}$ perteneciente al segundo nivel de atención de la Secretaría de Salud, de San Cristóbal de Las Casas, Chiapas. Especialmente aquellas vinculadas con la discriminación, y en particular con la orientación sexual y el itinerario socio/cultural del usuario del SAI, en la relación médico-paciente-institución. El campo de la atención en VIH-sida es susceptible de evidenciar algunas de estas problemáticas de manera más emblemática que en otras áreas de la atención médica. Para ello, a través de la técnica del estudio de caso y con un enfoque analítico socio-construccionista de carácter aplicado, analizo a continuación dos niveles que, desde el punto de vista de la realidad de estudio, se encuentran interconectados pero que, a efectos de análisis, dividiré en campos separados: a) Las representaciones sociales de los médicos ${ }^{4}$ proveedores, en el consultorio objeto

\footnotetext{
${ }^{1}$ La investigación fue llevada a cabo en el marco de una estancia posdoctoral en el CIESAS sureste y financiada por la Agencia Española de Cooperación Internacional y Desarrollo (AECID) del Ministerio de Asuntos Exteriores y de Cooperación español. Agradezco a ambas instituciones la posibilidad de llevar a cabo dicha investigación, así como los comentarios y recomendaciones, para la mejora del presente texto, realizados por los compañeros en el seminario interno, del CIESAS sureste, que tuvo lugar el 3 de abril del 2013.

${ }^{2}$ Son centros de atención en VIH integrados a los hospitales, a diferencia de los Centros Ambulatorios para la Atención del Sida y otras Infecciones de Transmisión Sexual, en un área específica interna de los mismos. Para saber sobre la historia de la creación y evolución de los SAI en México véase Secretaría de Salud, CENSIDA (2006).

3 Véase apartado metodológico para la cuestión del anonimato.

${ }^{4}$ Me remito a lo enunciado por, entre otros autores, Moscovici (1979). Si bien no existe un isomorfismo per se entre representaciones sociales y prácticas, el estudio de las representaciones sociales posibilita entender las dinámicas de las interacciones sociales y esclarecer cuáles son algunos de los determinantes de las prácticas, en este caso médicas, ya que la representación, el discurso y la práctica se generan mutuamente (Abric 2001). Aquí diferenciaré entre las representaciones, en los discursos, que son prácticas o conllevan una práctica, con una incidencia en la inclusión/exclusión a los cuidados de salud que proveen los actores sujeto de estudio, de aquellas que se enuncian sin un correlato, en este sentido, en las praxis clínicas.
}

de estudio, de prevención/atención ${ }^{5}$ de VIH-sida, con respecto a las prácticas sexuales (y preventivas de VIH-sida) y a los modelos explicativos del trinomio salud/enfermedad/atención de los sujetos y colectivos destinatarios. b) Las praxis de cuidados de los médicos en dicho consultorio.

\section{LA ANTROPOLOGÍA FRENTE A LA PREVENCIÓN/ATENCIÓN DEL VIH-SIDA Y EL INTERÉS DE ESTA INVESTIGACIÓN}

A lo largo de las primeras décadas de aparición del VIH-sida ${ }^{6}$ (1980 y 1990) se ha hecho una llamada, desde el ámbito médico, a la antropología para abordar la cuestión de su prevención. Esto ha tenido que ver, en diversos contextos como el africano o el actual de Chiapas que nos ocupa, fundamentalmente con la limitación de la ciencia biomédica a la hora de abordar cuestiones socioculturales que condicionan la transmisión de las ITS y su posible prevención, así como con la falta de medios, de tipo curativo y preventivo, en los denominados países en desarrollo, y especialmente en ciertas regiones del medio rural. La interpelación a la antropología ha buscado explicar variables como los modos de vida, los comportamientos sexuales o los gestos rituales (por ejemplo circuncisiones, escarificaciones, etc.) en la incidencia de la adquisición y propagación del VIH-sida. Esta perspectiva ha estado sostenida, como señala Fassin (2000), por una sobredeterminación cultural que ha tendido, con frecuencia, a ceñir las variables etiológicas de la enfermedad a unas prácticas reificadas, sin prestar atención a dimensiones como los contextos políticos y sociales en los que esta se desarrolla y rotura. Con el transcurso de los años dicha visión, desde cierta producción investigadora antropológica, ha ido cambiando para abordar de una manera más holística las explicaciones de la propagación e incidencia de la epidemia del VIH-sida y las ITS concibiendo aspectos explicati-

\footnotetext{
${ }^{5}$ El eje central de la investigación es el de la atención, en un consultorio médico, no obstante me refiero a la prevención/atención (control) ya que ni en el particular del VIH-sida ni en otras ITS se pueden disociar ambas acciones. Por ejemplo, entre otros, en la profilaxis y prevención para evitar la transmisión, en VIH y otras ITS, a los compañeros sexuales del paciente $y$, en algunos casos, la transmisión recurrente.

${ }^{6}$ En el año 1981 se diagnosticaron los primeros casos del Síndrome de Inmunodeficiencia Adquirida en los Estados Unidos de América.
} 
vos, como propuso en el particular de Haití Farmer (1992), menos reduccionistas, como los referentes a la economía política de los lugares en los que se desarrolla la epidemia.

En el caso que nos ocupa de México, ${ }^{7}$ y en particular de la región de los Altos de Chiapas, se han llevado a cabo investigaciones relativas a los hábitos sexuales y de uso de medidas de prevención de ITS entre colectivos considerados vulnerables como los migrantes, trabajadores y trabajadoras sexuales, o los hombres que tienen sexo con hombres (véase Reartes 2010, Freyermuth 2007, Evangelista y Kauffer 2007 o Castañeda et al. 1997). Dichas investigaciones, desde una perspectiva a menudo ecosistémica, permiten llamar la atención sobre los vectores de desarrollo de las ITS con relación a las trayectorias de los grupos vulnerables y los contextos de vulnerabilidad en los que se desenvuelven, y proponen un valioso material para implementar intervenciones eficaces, desde diversos ámbitos, en materia de prevención de ITS y acceso a las medidas preventivas/curativas y de control (en el caso actual del VIH-sida).

En lo que se refiere al análisis de las prácticas y representaciones de los médicos, en los servicios de prevención/atención de VIH-sida que operan en la región, con respecto a los pacientes y su relación con las modalidades que la exclusión/inclusión en el acceso a dichos servicios adquiere en su seno, casi no existen en la actualidad investigaciones sobre la

\footnotetext{
${ }^{7}$ En el año 1983 se registra el primer caso de sida en México. La epidemia en el país es predominantemente de transmisión sexual, ya que del total de los casos notificados históricamente de sida y seropositivos al VIH en los que se conoce su categoría de transmisión, 94\% de los casos notificados de sida desde los inicios de la epidemia pertenecen a la categoría de transmisión sexual (ya sea homosexual, bisexual o heterosexual), mientras que en el caso de los que continúan como seropositivos al VIH la cifra es de $97 \%$. De los casos notificados de sida en hombres, cuya categoría de transmisión se conoce, $32 \%$ refieren una categoría de transmisión por relaciones sexuales homosexuales y $22 \%$ bisexuales; $41 \%$ indica la vía heterosexual (cabe considerar que podría estar sobre reportado dado que muchos hombres no se asumen homosexuales aunque tengan sexo con otros hombres), $2 \%$ por uso de drogas inyectables y otro $1 \%$ por transmisión vertical. Por otra parte, $87 \%$ de los casos registrados de sida en mujeres refieren una categoría de transmisión por relaciones sexuales heterosexuales, $6 \%$ indica la vía de transmisión vertical, otro $6 \%$ por transfusión sanguínea; y $1 \%$ por uso de drogas inyectables (CENSIDA 2012b). Diversas han sido las investigaciones en los ámbitos clínicos y epidemiológicos llevadas a cabo en el país (véase, entre otros, CENSIDA, censida. salud.gob.mx/).
}

cuestión. ${ }^{8}$ Algunos trabajos, puntuales, han abordado la discriminación y el estigma por parte de los trabajadores de la salud (en áreas diversas de la atención médica y no relacionadas con la atención de VIH-sida) en México, desde el punto de vista de la relación médico/paciente. Uno de los pocos antecedentes, en el país, que vincule los discursos de los trabajadores de la salud y su contenido «científico» y de creencias y mitos con respecto al VIH-sida, con sus prácticas sanitarias y la discriminación que en ellas subyace es el trabajo de Infante et al. (2006). Otros que, en este contexto, han abordado la cuestión de la adherencia terapéutica de los pacientes con VIH-sida a los antirretrovirales, desde una perspectiva cuantitativa, señalan la ausencia y necesidad de investigaciones cualitativas (Balandrán et al. 2011) para poder entender los efectos excluyentes, en la adherencia terapéutica, que se desprenden de la relación entre médico/paciente ${ }^{9}$. Es significativo, en este sentido, que en el panorama general de México, el segundo país de América Latina con mayor número de personas viviendo con VIH (CENSIDA 2009a), el acceso universal al Tratamiento Antirretroviral Altamente Supresivo (TAR), logrado en 2004 (CENSIDA $2009 b$ ), no parece haber incidido en un descenso de la mortalidad ocasionada por el sida, de un $4.3 \%$ por cada 100000 habitantes en el año 2000 y un $4.5 \%$ en 2010 (CENSIDA 2012a). ${ }^{10}$ Algunas de las causas que desde diversos organismos (como CENSIDA 2009a) se barajan sobre este fenómeno son la falta de detección oportuna y de adherencia al tratamiento antirretroviral. Una de las variables, que abordo aquí, incidentes en la problemática de la adherencia ${ }^{11}$ y la

\footnotetext{
${ }^{8}$ Algunas investigaciones, en otras regiones de Chiapas, sí han explorado cualitativamente la percepción de los médicos con respecto a su práctica profesional, en ámbitos generales, y a la relación médico-paciente (véase, por ejemplo, Álvarez y Álvarez 2011).

${ }^{9}$ Si bien en el presente documento no se menciona otro de los aportes de interés de esta investigación, con respecto a la mencionada, fue la adopción de una perspectiva relacional (que permite un elemento añadido, principal, de validación) al incluirse las representaciones de los usuarios, y no solo las de los médicos, relativas a las prácticas de cuidados del personal de salud y a su acceso a las mismas.

${ }^{10}$ A finales de 2011 se tenían notificadas cerca del $67 \%$ (considerando los registros vivos) de las 147000 personas viviendo con VIH que se estimaba había en el país con base en el modelo de ONUSIDA. Para mediados de 2012 podrían ser alrededor de 150000 (CENSIDA 2012b).

${ }^{11}$ La adherencia será considerada como «el grado en el que el comportamiento de una persona -tomar un medicamento, seguir
} 
falta de detección oportuna es la relación médico/ paciente en la arena organizativa/institucional de la provisión de cuidados en ITS, y los procesos, que de ella se derivan, excluyentes o incluyentes a dichos cuidados.

Por otro lado, en lo que se refiere a la escasez de trabajos relativos a las discriminaciones en la relación personal de salud/paciente y en particular la de tipo racista, Menéndez (2006) señala que en México no existen, en las últimas tres décadas, estudios ni intervenciones que traten de indagar sistemáticamente sobre la presencia de aspectos racistas en dicha relación e intenten modificarla. Esto sucede en un panorama en el que el racismo, según el autor, constituye un fuerte componente de las relaciones de hegemonía/subalternidad que se desarrollan, cotidianamente, a través de procesos de salud/enfermedad/atención. Ahondar en las representaciones y prácticas de los médicos proveedores de cuidados en VIH-sida, por medio de esta investigación, conlleva aportes de interés con relación a los modos de acceso, inserción y exclusión de las poblaciones usuarias a estos consultorios médicos, y a la adaptación de las miradas y praxis de dicho personal de salud, en la búsqueda de una mejora preventiva/curativa y de control en la lucha contra las ITS.

\section{PANORAMA EPIDEMIOLÓGICO Y PRESENCIA DE CONSULTORIOS DE PREVENCIÓN/ ATENCIÓN DEL VIH-SIDA EN SAN CRISTÓBAL DE LAS CASAS}

En muchas áreas poblacionales del estado de Chiapas las problemáticas relativas al VIH-sida no han sido constatadas con eficacia, ni actualmente lo son,

un régimen alimentario y ejecutar cambios del modo de vida- se corresponde con las recomendaciones acordadas de un prestador de asistencia sanitaria. En este sentido, es necesario tener en cuenta la conformidad del paciente, y su participación activa, respecto a las recomendaciones (OMS 2004). Aquí me referiré a adherencia o apego, indistintamente, a la consulta médica como la afiliación o vínculo que genera el paciente con dichas recomendaciones, especialmente el seguimiento del tratamiento $\mathrm{ARV}$, que en ella tienen lugar. Algunas de las variables biopsicosociales y culturales que en ello inciden son las condiciones socioeconómicas del paciente, su capital social, los modelos culturales de la curación y la enfermedad de los pacientes y el personal de salud, las características personales del paciente (edad, sexo...), el sistema de cuidados, la calidad de la relación médico-paciente, factores clínicos, etc. (para saber más, véase Castro 2005). debido a la carencia de dispositivos de detección, prevención y atención. Sin embargo, a raíz de la intensificación de mecanismos de detección en determinados sectores, fruto de programas (algunos de los cuales dependen del Instituto de Salud del Estado de Chiapas) como, por ejemplo, el de detección del cáncer cervicouterino, desde hace unos años se viene cuantificando un aumento de las ITS, y en particular del VIH-sida' ${ }^{12}$ (véase CENSIDA 2009a, 2012a), en ciertos colectivos vulnerables. En términos epidemiológicos Chiapas se encuentra en el octavo lugar, en el conjunto de México, en cuanto a número de casos acumulados de VIH-sida (de los reportados por las instituciones oficiales) y en el cuarto lugar en cuanto al número de defunciones. En este estado, proporcionalmente, existe un mayor número de hombres que de mujeres, de 3 a 1 , que padecen la enfermedad siendo la transmisión sexual la modalidad principal reportada. Con los datos estadísticos de los que se dispone en la actualidad, en la región, se puede considerar la epidemia del VIH-sida como concentrada en grupos vulnerables. En esta categoría se encuentran, entre otros, las trabajadoras y trabajadores sexuales, hombres que tienen sexo con hombres o los migrantes (véase Reartes 2010, Infante et al. 2009, Leyva y Quintino 2007 o Cáceres 1999). El rango de edad en el que se presentan más casos de VIH-sida es el de personas entre 20 y 39 años (CENSIDA 2009a, 2012a). En cuanto a otras ITS se han detectado, como mencionaba, un aumento en los últimos años, siendo $97.7 \%$ en mujeres y $2.3 \%$ en hombres (diferencia que, probablemente, remite a los destinatarios de los programas citados y a las condiciones asintomáticas de ciertas ITS en hombres). Las cinco ITS más frecuentes en la región son: candidiasis urogenital (64.59\%), tricomoniasis urogenital (32.29\%), virus del papiloma humano (1.9\%), herpes genital $(0.47 \%)$ e infección gonocócica genitourinaria $(0.27 \%)$ (Aguilar y Jiménez 2007). En lo referente a la etnicidad esta no se reporta en el tratamiento o la defunción por VIH-sida,

\footnotetext{
${ }^{12}$ Los criterios de actuación de los componentes del Sistema Nacional de Salud, en términos de prevención, atención y control de las ITS/VIH/sida a nivel nacional, están recogidos en la Norma Oficial Mexicana para la Prevención y Control de la Infección por Virus de Inmunodeficiencia Humana NOM-010SSA2-1993 (www.salud.gob.mx/unidades/cdi/nom/010ssa23. html) y en la NOM-039-SSA2-2000 (bvssida.insp.mx/ archivos/ nomits2002.pdf).
} 
con lo cual no se dispone de datos estadísticos en este sentido. ${ }^{13}$

Desde mediados de los 90 San Cristóbal de Las Casas ha presenciado un aumento de la heterogeneización sociocultural de su población. Por un lado, en la experimentación de uno de sus más notables movimientos contemporáneos de recepción de migrantes expulsados por los conflictos religiosos y políticos, de sus comunidades de origen, en los Altos de Chiapas $^{14}$ (Robledo 2009). Y por otro, en el aumento de población no autóctona ${ }^{15}$ fruto de la proliferación de Asociaciones Civiles (AC) internacionales y proyectos estatales. ${ }^{16}$

Dentro de las iniciativas llevadas a cabo por el sector de la sociedad civil local y nacional, y en el ámbito de las AC internacionales, actualmente se realiza un trabajo más enfocado a las campañas iti-

\footnotetext{
${ }^{13}$ Algunas de las razones de esto en México, fenómeno que acontece en el conjunto de las poblaciones indígenas en Latinoamérica, tienen que ver con, por ejemplo, no concebir la salud incluyendo a los pueblos indígenas. Los estereotipos sociales sobre quién es un indígena y cómo viven (lo cual incluye su orientación y prácticas sexuales entendidas como predominantemente heterosexuales). La intención, errónea, de no tratar de estigmatizar más a estas poblaciones. O la suposición de que las políticas universalistas, en salud, en el medio rural tienen en cuenta a la población indígena sin observar su especificidad sociocultural en un país marcado por la discriminación y el racismo (Ponce 2011). Pese a ello he detectado que de los 122 pacientes, en los Altos de Chiapas, dados de alta actualmente en el «SALVAR» (Sistema de Administración Logística y Vigilancia de Antirretrovirales), y teniendo en cuenta que solo contabiliza los dos últimos años desde que se creó el programa, han abandonado el tratamiento antirretroviral 32 personas, las cuales son en su mayoría indígenas ( $43 \%$ del total de pacientes indígenas, definidos por hablar una lengua indígena, dados de alta en el «SALVAR» (Responsable del programa de VIH-sida en los Altos, entrevista 2012).

${ }^{14}$ La región de los Altos de Chiapas, que jurisdiccionalmente (y desde el punto de vista de las competencias en salud) es denominada el área o región II del estado de Chiapas y está dividida en 18 municipios, cuenta con $52.7 \%$ de población hablante de una lengua indígena. La población total de San Cristóbal de Las Casas es de 132421 personas de las cuales 47890 hablan alguna lengua indígena. Entre los años 1990 y 2000 la tasa de crecimiento anual fue de un $4.10 \%$ (INEGI 2005).

${ }^{15}$ Por autóctona me refiero a aquella persona oriunda de San Cristóbal de Las Casas.

${ }^{16}$ En su mayoría colaboradores en estos organismos provenientes, principalmente, de otras regiones de México, así como, por ejemplo, de países europeos o Estados Unidos. El movimiento zapatista, y su llamada de atención sobre algunos de los problemas experimentados por la población indígena, ha sido una de las causas principales de dicho fenómeno. A ello hay que sumarle el aumento del turismo nacional y foráneo.
}

nerantes de sensibilización y prevención en salud sexual, a excepción de dos AC que proveen atención en su seno. ${ }^{17}$ En el escenario institucional estatal, ${ }^{18}$ de San Cristóbal de Las Casas, existen consultorios de prevención/atención de VIH-sida (por medio de médicos generalistas, especialistas o ambos casos) en el Instituto Mexicano del Seguro Social y otras instituciones adscritas a las diferentes modalidades de derechohabiencia. Para los no derechohabientes, $86.2 \%$ de la población en los Altos de Chiapas, la prevención/atención de VIH-sida se da en clínicas del primer y segundo nivel. ${ }^{19}$ Dos son los motivos por los que me ceñiré a la clínica I, mencionada, destinada a población abierta en el ámbito institucional. Por una parte, puesto que es la única, de la Secretaría de Salud, que centraliza el tratamiento de VIH-sida en la región. Por otra, debido al alto porcentaje de no derechohabientes, y la relación de sus características socioeconómicas y culturales (de bajos ingresos y con amplia presencia de población indígena) con ciertos factores potencialmente excluyentes a los cuidados de salud. De ello, y de las características de esta clínica y de los servicios de salud en su seno, sujeto de estudio, me ocuparé con más detalle posteriormente.

\section{METODOLOGÍA}

La temporalidad de la investigación, cuyos resultados aquí se discuten, comprende el periodo de marzo de 2010 a diciembre del 2012. Por sus características y las potenciales implicaciones para los actores en ella involucrados, no se menciona en el documento el nombre real de la clínica sujeto de estudio, así como tampoco de quién se obtuvo la información en las entrevistas ni otros datos que puedan revelar el anonimato de los actores. Se ha hecho uso del consentimiento informado para todas las entrevistas y se ha discutido el uso de las técnicas de investigación

\footnotetext{
${ }^{17}$ Tanto en este particular como en el institucional estatal, y sus diferentes niveles y modalidades (IMSS, ISSSTE, etc.) de atención, son derivados, en el caso de detectarse VIH-sida, a la clínica I (de la Secretaría de Salud) para la confirmación de la prueba de detección, el registro del programa de notificación epidemiológica «SUAVE» y, de no ser derechohabientes, el seguimiento y tratamiento.

${ }^{18}$ Por otra parte, existe una proliferación, en la práctica médica privada, de consultorios (en farmacias o particulares) que atienden, entre otras problemáticas, ITS.

${ }^{19}$ Los únicos existentes en la ciudad.
} 
con expertos en el área de la ética en investigación y antropología médica.

Las técnicas de investigación etnográfica han sido las siguientes:

- 29 entrevistas en profundidad a los médicos de este (el SAI ) y otros consultorios de atención en ITS, colaboradores externos y los psicólogos vinculados a ellos, ${ }^{20}$ así como a los directores de departamento y de las clínicas; expertos, pertenecientes al ámbito académico y de las AC en el sujeto de estudio; jefes de la jurisdicción sanitaria en el programa de VIH y tuberculosis; pacientes de los consultorios de prevención/ atención de VIH-sida (pacientes mestizos e indígenas, hombres y mujeres de ámbitos urbanos y rurales, con edades entre los 18 y los 45 años ${ }^{21}$ ) y usuarios simulados.

- Usurarios simulados: ${ }^{22}$ se ha capacitado a ocho usuarios simulados en cuestiones relativas a la

\footnotetext{
${ }^{20}$ En el caso de los médicos: en la clínica I es un hombre de 46 años, originario de San Cristóbal de Las Casas, y una mujer, voluntaria en la consulta y originaria del DF, de 27 años. En otra clínica, de la Secretaría de Salud de la ciudad, una mujer de 50 años, originaria de San Cristóbal de Las Casas, que atiende un consultorio de prevención/atención en salud sexual. Y en una clínica, de la sociedad civil, dos médicos, hombre y mujer, de 28 y 31 años de edad. Los psicólogos son cinco mujeres y un hombre. Los criterios de selección muestral se han ceñido a la obtención de la información, relativa al eje de la investigación, con el objetivo de poder contrastarla, entre los sujetos entrevistados y los consultorios, y triangular con otras fuentes de obtención de datos.

${ }^{21}$ Incluir a ambas poblaciones en un amplio rubro de edades ha posibilitado obtener elementos de contraste con respecto a la incidencia de las variables socioculturales en las representaciones y prácticas de los médicos.

${ }^{22}$ La estrategia del usuario simulado se ha utilizado en ámbitos diversos de la investigación y evaluación de la calidad de servicios, entre otros, en salud (véase, desde una perspectiva crítica, Rosenhan (1973), o aquellas que se utilizan para la formación del personal de salud) o en ámbitos laborales más amplios con el objetivo de evaluar el desempeño profesional de los trabajadores. A su vez, ha sido utilizada, en el campo de la investigación periodística y en ciencias sociales, desde una perspectiva crítica con el fin de denunciar delitos y/o evidenciar situaciones de explotación y abuso (véase Wallraff 1987). Otra área ha sido la de la investigación en el campo de las religiones (Festinger et al. 1970, Truzzi 1974 o Wallis 1976). Desde esta perspectiva crítica o no en ocasiones fueron los propios investigadores los que ocultaron su identidad o, como en la presente investigación, son personas formadas para desempeñar el papel, puntual, de usuario de un servicio.
}

discriminación y estigma ${ }^{23}$ en los cuidados de salud. ${ }^{24}$ Posteriormente se desarrolló un guion de observación e interacción, que produjeron los propios usuarios en función de sus vivencias previas, y se realizaron dos grupos focales, uno al comienzo y otro al final de la experiencia. A su vez cumplimentaron un cuestionario con preguntas cerradas tras cada visita a las clínicas (estas comprendieron de tres a seis visitas por usuario, dependiendo del acceso a las consultas, su devenir y la obtención de la información). El perfil de los usuarios fue el de jóvenes entre 18 y 30 años tseltales y tsotsiles (cuatro mujeres y cuatro hombres).

- Participación en reuniones y encuentros del personal médico en las clínicas de dos cabeceras municipales de comunidades aledañas a la ciudad de estudio (desde las que se deriva a algunas personas con diagnóstico de VIH-sida).

- Participación en reuniones con AC en Chiapas, que trabajan en cuestiones de salud sexual.

- Visitas a las comunidades y casas de los pacientes que dejaron de acudir a los consultorios del SAI y al tratamiento antirretroviral; por motivos de acceso y tiempo se realizaron mayormente en San Cristóbal de Las Casas y San Juan Chamula.

- Visitas a la clínica de la cabecera municipal de San Juan Chamula y a dos clínicas en dos parajes del mismo municipio.

- Conversaciones informales con promotores de salud, personal directivo de hospitales y responsables políticos y administrativos en este campo, así como con familiares de personas viviendo con VIH-sida.

\section{EL SAI Y SU CONSULTORIO MÉDICO}

La clínica I, perteneciente al segundo nivel de atención, ${ }^{25}$ centraliza el cuidado y seguimiento de los

\footnotetext{
${ }^{23}$ Me remito al trabajo de Goffman (2006 (1963)).

${ }^{24}$ A diferencia de los pacientes del consultorio su capacitación específica en cuestiones de estigma y discriminación permite, en muchos casos, obtener datos empíricos más precisos en este sentido.

${ }^{25}$ Fundado a principios de los años setenta, se encuentra ubicado en el centro de la ciudad. Sus especialidades básicas son: ginecoobstetricia, cirugía, medicina interna cuidados y pediatría. Cuenta con 30 camas censadas y con un área de urgencias (Argüello y Freyermuth 2004, Gobierno del Estado de Chiapas 2012). El hospital opera las 24 horas del día de lunes a vier-
} 
pacientes portadores de VIH-sida (en la jurisdicción número dos, que, además de las comunidades de su competencia, abarca la ciudad de San Cristóbal de Las Casas) y atiende y da tratamiento a pacientes con otras ITS, hombres y mujeres, en el Servicio de Atención Integral para personas que viven con VIH-sida (en adelante SAI), el cual está constituido por un consultorio médico, externo, específico para ambos casos y un consultorio de psicología. Dicho consultorio médico ha sido el objeto de estudio etnográfico central de la clínica.

El SAI se encuentra ubicado en la mencionada clínica cuyas consultas están destinadas casi exclusivamente a mujeres (ginecología) y a niños (pediatría). La mayor parte de los pacientes acuden al SAI derivados de otros servicios de salud, en este caso con una prueba diagnóstica de VIH-sida positiva previa, para realizarse el examen de confirmación, western blot, y comenzar el tratamiento ARV. ${ }^{26}$ Pocos son los que acuden por su propia cuenta para demandar información o hacerse pruebas diagnósticas. ${ }^{27}$ El doctor tiene una formación como médico general. Sus competencias en infectología las ha adquirido por medio de la experiencia y las capacitaciones que ha cursado a lo largo de los años. ${ }^{28}$ Desde hace más de diez años el médico trabaja solo

nes en turnos matutinos, de 7:00 a 15:00 hrs., y vespertinos, de 14:30 a 22:30 hrs. (con guardias en la noche de los médicos interinos). El médico que atiende el Servicio de Atención Integral (en VIH-sida) no tiene especialidad, actualmente, si bien trabaja allí desde que fue creada la consulta, en 2001.

${ }^{26}$ Muchos pacientes con VIH-sida, son derivados (desde diversos municipios de la región de los Altos y de la Selva Lacandona (Palenque y Ocosingo) al hospital de Las Culturas debido a patologías asociadas (como la tuberculosis) y en estado crítico. Según he podido constatar, por medio de entrevistas a expertos, esta es una de las formas más recurrentes de diagnóstico. Ello remite a la infradetección existente por parte de los médicos de primer nivel, quienes pocas veces les proponen pruebas de detección, en muchos casos por falta de sensibilización y capacitación con respecto a las características del VIH y a los perfiles (especialmente en contextos en los que no se han detectado históricamente altas tasas de VIH) de vulnerabilidad de ciertos pacientes. Tanto en estos casos como en los que acuden directamente a la consulta el estadio de la enfermedad suele ser avanzado (Entrevista a médico del SAI en 2011).

${ }^{27}$ Una modalidad de derivación a la consulta en situaciones especiales, como es el caso de la violencia de género, acontece por medio de algunas asociaciones civiles, las cuales acompañan a las personas que requieren atención médica.

${ }^{28}$ La especialización de los médicos tratantes también es un factor de peso en el éxito del tratamiento (véase CENSIDA, INSP y Secretaría de Salud, 2009). en la consulta. En este sentido, no tiene enfermero/a ni ayudante, más allá de una voluntaria que estuvo apoyándolo durante unos meses. ${ }^{29}$ Tampoco cuenta con un traductor o intérprete lingüístico/cultural a pesar de ser el español su único idioma. ${ }^{30} \mathrm{El}$ médico debe acudir a capacitaciones en áreas como la de los tratamientos y esquemas ARV; sin embargo, por lo que he podido comprobar, en ocasiones no lo hace (y esto no es supervisado ni tiene repercusión alguna en su desempeño profesional). En lo que respecta a la participación de los usuarios de la consulta en el proceso salud/enfermedad/atención-control en el SAI no existe un grupo de autoapoyo, ni actividad colectiva alguna entre los pacientes. ${ }^{31}$ Tampoco hay una implicación de la sociedad civil en el monitoreo y la rendición de cuentas del servicio. ${ }^{32}$ En cuanto a la movilidad del médico, sus funciones comprenden acudir al hospital de las Culturas, en caso de ser llamado al no poderse realizar una derivación de los pacientes en estado de gravedad, así como ir a las comunidades para llevar a cabo visitas de reenganche con aquellos que dejaron de acudir al SAI . El médico, por diversas razones que aquí no explicaré, no viaja nunca a las comunidades, lo cual, como se verá después, repercute en su visión, centrada en el confinamiento espacial de la consulta, sobre las prácticas y contextos de vida de ciertos pacientes.

${ }^{29}$ El médico justifica trabajar solo con el argumento de la defensa del anonimato de los pacientes. Sin embargo, por lo que he podido detectar, existe una suerte de rechazo por parte del personal de salud para trabajar en este tipo de consultas al temer un riesgo (infundado) de transmisión del VIH-sida, ocupacional.

${ }^{30}$ Debiendo acudir el paciente que no habla español con un acompañante que ejerza de traductor. Esto conlleva diversas problemáticas en el acceso del paciente al servicio si no lo encuentra, y, entre otras, en la falta de control metodológico y de la información obtenida en la traducción (realizada de forma no profesional por alguien, por lo general, del entorno familiar del paciente).

${ }^{31}$ Lo cual ha sido propuesto en diversas ocasiones por los pacientes y es justificado por el médico bajo el argumento del miedo a la pérdida del anonimato que ellos albergan. En mi opinión, esto tiene más que ver, como sucede en otros lugares, con el temor al empoderamiento de los pacientes por parte del médico (y la no existencia de incentivos u obligaciones para su creación), además de (como menciona Menéndez 2009) con una concepción jerarquizada en la organización del sector salud y una exclusión de la participación social al no considerarse un asunto biomédico.

${ }^{32}$ Como en el caso del "grupo multisectorial en VIH-sida e ITS del estado de Veracruz», fundado por Patricia Ponce en 2002. 


\section{REPRESENTACIONES Y JUICIOS ÉTICOS CON RESPECTO A LAS MODALIDADES DE ADQUISICIÓN DEL VIH-SIDA Y PRAXIS MÉDICAS. CÓMO OPERA LA SELECCIÓN SOCIAL EN LA CLÍNICA}

En muchas sociedades del mundo el VIH-sida (tal y como menciona, entre otros autores, Comaroff 2007) ha sido utilizado para producir una imagen de amoralidad y un juicio de valor con respecto a las personas que sufren la enfermedad. De igual manera ha sucedido con los grupos sociales, las regiones y países con mayor prevalencia. En el caso particular que nos ocupa el juicio de valor, ligado a las formas de adquisición del VIH-sida, reúne las particularidades de una selección social ${ }^{33}$ que se realiza en el consultorio, y que la propia enfermedad ya ha llevado a cabo previamente en las poblaciones vulneradas, ${ }^{34}$ operando en diversos niveles de exclusión a los cuidados de salud. A diferencia de las modalidades de existencia como imágenes apuntaladas o no en la experiencia directa, ${ }^{35}$ de las representaciones con respecto al VIH en la población que no ha convivido con la enfermedad, el juicio de valor articulado en torno a las representaciones sociales que se tienen de los pacientes y sus prácticas sexuales y de prevención de ITS opera en los médicos (que trabajan en salud sexual) sobre la base de la experiencia cotidiana, la cual está mediada por una serie de interpretaciones que realizan de los hechos a los que se confrontan, en este caso, en su práctica profesional. $\mathrm{Y}$ sucede en un conjunto de plantillas culturales, profesionales y relativas a los itinerarios personales

${ }^{33}$ Por selección social me refiero aquí al efecto excluyente/ incluyente que posée el juicio de valor, acompañado de prácticas convergentes en torno al mismo, que el médico emite con respecto a los modos de interacción, comportamentales, y al origen étnico y social del paciente. La selección social actúa por medio de la discriminación, en un contexto de recursos limitados (y concebido, en este sentido, significativamente como tal por los actores), entre aquellos pacientes que, por sus trayectorias socio/ culturales y/o prácticas/orientación sexual, son sometidos a un tipo de trato u otro. De ello hablaré más adelante.

${ }^{34}$ Por su trayectoria socio/cultural y/o factores como la orientación o prácticas sexuales de la población que vive con VIH-sida, la cual es reforzada por los condicionantes socio/económicos, la discriminación y el trato diferencial del conjunto de la sociedad y, en este caso, el personal de cuidados al interior de la consulta.

${ }^{35} \mathrm{Me}$ refiero a aquella en la que se conoce a alguien que sufre, o ha sufrido, esta enfermedad. (no profesionales), a partir de las cuales orienta y produce el médico su acción e interpretación y que más allá de encontrarse separadas inexorablemente (incluso por procesos ritualizados de pretendida disección del ámbito privado/público) se entrecruzan. $\mathrm{Y}$ al hacerlo evidencian, como he podido comprobar en diversos ámbitos de observación, ${ }^{36}$ las posiciones que se ocupan, en los campos sociales y las prácticas y disposiciones en juego, en la distribución de los capitales (sociales, económicos, simbólicos y culturales) de los actores. Especialmente me refiero, en este caso, al origen socioeconómico y cultural del médico y a la presión adaptativa (causa y producto de la selección social) que supone la llegada de un paciente que representa para él, en el contexto del consultorio y por diferentes razones, una alteridad. El caso del VIH-sida, por sus características en cuanto a su modo de transmisión dominante ${ }^{37}$ por vía sexual, y las consideraciones morales y el estigma que subyace en él ejemplifica el isomorfismo, negado bajo el criterio de los campos autónomos y técnicos profesionales, de la clasificación social/ideológica y la clasificación clínica/técnica del paciente.

Podemos reconocer en dos tipos de escisiones y sobredeterminaciones, en un ejercicio de reificación técnica del saber, las bases sobre las que se asienta la selección social por parte del médico: $a$ ) la relativa al diagnóstico y la entrada a ser (en el rito, que produce un tipo específico de diferenciación biológica y social, del diagnóstico) paciente. Esto es, desde la perspectiva del médico: paciente portador de un virus que produce un síndrome crónico cuyas complicaciones, solo combatidas con un acertado tratamiento ARV, ${ }^{38}$ llevan a la muerte. Por otra parte, sujeto a ser considerado como un portador de responsabilidades (los derechos ya los tenía antes del diagnóstico) que se traducen de su nueva condición social. Lo cual genera un nuevo tipo de relación con el médico, de por vida y dependiente de una sola modalidad de control centrada en el tratamiento ARV, y unas nuevas expectativas (de este como representante del sector salud) con respecto a su vida y a su condición vulnerable, y especialmente a las conductas potencialmente amenazantes (para sí

\footnotetext{
${ }^{36}$ Con médicos de diversas especialidades principalmente, pero también en la propia observación de mi práctica profesional como antropólogo.

${ }^{37}$ A continuación se problematiza esta cuestión.

${ }^{38}$ Para más información sobre el tratamiento ARV véase Hoffman (2006, citado en CENSIDA 2012b).
} 
mismo o para los otros), ${ }^{39}$ esto es, principalmente las prácticas sexuales. ${ }^{40}$ Es este último factor el que lleva a la segunda escisión: $b$ ) el modo de transmisión/ adquisición.

En el caso de los consultorios específicos de atención de VIH-sida (y de este en concreto) el diagnóstico, a excepción de algunos pacientes que acuden por otras ITS, opera, como modalidad de acceso al consultorio, en la confirmación de la prueba ya realizada previamente, en el nuevo diagnóstico o en el reenganche o incorporación de algún paciente diagnosticado con anterioridad. Lo cual, siendo un elemento de dicha selección social por parte del médico -puesto que desconoce las situaciones previas a la consulta y evalúa solo aquello que puede observar desde su confinamiento espacial-, introduce a su vez una distinción en términos de la confianza que, de cara al apego al tratamiento, el paciente suscita. Y está articulada, desde la perspectiva del médico y con respecto a dicha confianza sinónimo de un trato diferencial, con su deseo de vivir, su responsabilidad para con aquellas personas que dependen de su existencia (hijos, etc.) y de ser el paciente alguien dependiente (por ejemplo, un niño que acude con su padre o madre), ser responsable, en este sentido, de su propia vida o muerte. ${ }^{41}$

Por medio del saber/poder que se legitima en mecanismos de consagración institucional reflejados en títulos y profesiones (el médico) y en posiciones sociales y roles que se erigen bajo el criterio de un saber experto versus un saber profano, el médico reproduce dicha selección social de los pacientes bajo cuatro criterios de clasificación:42 diagnóstica, clínica, basada en el estado funcional e ideológica.

${ }^{39}$ Esto sucede en otras enfermedades también, atribuibles (desde una lógica que dirige la responsabilidad de la curación y la enfermedad hacia el sujeto) a conductas «de riesgo», modos de vida, etc. Sin embargo las características del VIH-sida, su cronicidad, estigmatización y letalidad, lo hacen especialmente distintivo.

${ }^{40}$ También implica cuestiones problemáticas como la información, o no, de su seropositividad en contextos en los que podría existir riesgo de transmisión por vía sanguínea (dentistas, operaciones, etcétera).

${ }^{41}$ Esta suele ser una de las razones que se esgrime en la consulta, por lo que he podido recoger en los testimonios de pacientes y fruto del temor del médico al desapego, cuando es un hombre portador del VIH-sida y tiene una familia (la cual puede ser portadora a su vez).

${ }^{42}$ Aquí me remito a lo señalado por Fernández-Rufete (2000) (quien retoma a Bourdieu) con respecto a la clasificación en su dimensión de signos distintivos destinados a ser valorados y
Expondré a continuación algunos de los hallazgos de las representaciones sociales y sus correlatos en las praxis médicas, haciendo hincapié en la clasificación ideológica, que tienen lugar en el consultorio:

\section{LOS HOMBRES SON CULPABLES, PERO SI SON HOMOSEXUALES... ¡TODAVÍA MÁS!}

La existencia de culpabilización/exoneración del paciente $^{43}$ con VIH-sida, por parte del médico con respecto a su culpa por omisión de la prevención de adquisición, en cuanto a la representación de la modalidad de la transmisión, el género ${ }^{44}$ y el origen socio/cultural del paciente, opera con respecto al siguiente esquema, de menor a mayor grado de estigmatización, en el consultorio que es sujeto de estudio: 1) La vía de adquisición por transfusión sanguínea, exposición ocupacional ${ }^{45}$ y la perinatal (de madre a hijo). 2) La mujer que adquiere la enfermedad en las relaciones sexuales con su marido. 3) El hombre que contrae la enfermedad por vía heterosexual (por ejemplo, al acudir a trabajadoras sexuales sin hacer uso del preservativo). 4) La adquirida en relaciones homosexuales. ${ }^{46}$

apreciados, no siendo solo síntomas que deben de ser comprendidos o descifrados, así como signos de autoridad destinados a ser creídos y obedecidos.

${ }^{43}$ Lo cual he podido constatar en conversaciones con epidemiólogos en países europeos con respecto a sus propias representaciones (y ha sido debatido en diversos estudios (ver, por ejemplo, en el contexto de Veracruz, Macías 2012).

${ }^{44}$ Una de las representaciones más comunes entre los médicos entrevistados con respecto al vector de transmisión es la consideración de que en la mayor parte de los casos es el hombre el que transmite el VIH-sida a la mujer. Dicha representación parte de la idea de que el hombre, especialmente en ciertas situaciones como en el contexto migratorio, es promiscuo, mientras que la mujer, casada, es monógama. En este caso, la representación del vector de transmisión, hombre-mujer, exonera a las mujeres, culpabilizando a los hombres, a través de una concepción pasiva y sumisa de la sexualidad de la mujer, coherente con una estructura canónica de la familia (en el sentido mencionado por Turner 1987) y las relaciones entre géneros.

${ }^{45}$ La exposición ocupacional, principalmente ocasionada por pinchazos con agujas, suele ser otra de las demandas de tratamiento profiláctico en la consulta.

${ }^{46}$ En lo que respecta a la vía intravenosa, debido a los pocos (en este contexto) pacientes con VIH-sida por dicha modalidad de adquisición, no tengo datos para incluirla en el esquema anterior. Lo cual no quiere decir que no exista, varios han sido los pacientes que han mencionado haber consumido drogas por esa vía, sino más bien que esta forma de transmisión no ha sido considerada, desde el criterio epidemiológico en la entrevista clínica, como principal frente a la vía de transmisión sexual. 
Esta clasificación podemos articularla, en este caso específico, con la correspondencia entre criterios de clasificación de tipo médico y social enunciada, en el contexto español, desde los hallazgos de Fernández-Rufete (2000):

\begin{tabular}{|l|l|}
\hline $\begin{array}{l}\text { Principios de clasificación } \\
\text { médica basados en vías de } \\
\text { transmisión del VIH-sida }\end{array}$ & $\begin{array}{l}\text { Principios de clasificación } \\
\text { social basados en vías de } \\
\text { transmisión del VIH-sida }\end{array}$ \\
\hline $\begin{array}{l}\text { Contagio por práctica } \\
\text { homosexual }\end{array}$ & $\begin{array}{l}\text { Anormalidad, perversión, des- } \\
\text { viación, prácticas no naturales }\end{array}$ \\
\hline Contagio heterosexual & $\begin{array}{l}\text { Promiscuidad, irresponsabili- } \\
\text { dad, victimismo }\end{array}$ \\
\hline $\begin{array}{l}\text { Contagio vía transmisión sanguí- } \\
\text { nea (hemofilia y transfusiones) }\end{array}$ & Victimismo e inocencia \\
\hline
\end{tabular}

Por otra parte, existe un vector en las representaciones del médico con respecto al origen de la persona, autóctona o extranjera, vinculada con el riesgo potencial de ser portador del VIH-sida: ${ }^{47}$

Extranjero/migrante: promiscuo, liberal, prácticas sexuales inseguras, consumo de alcohol y drogas.

Autóctono/sedentario: conservador, monógamo o polígamo dentro de un margen de seguridad que remite a las restringidas redes de contacto en cuanto al número y al imaginario de la seguridad geográfica endogámica, del compañero/a sexual, si se compara con el extranjero/migrante. Menos consumo de drogas y alcohol.

Autóctono/migrante: conservador influido por las prácticas, ideas y referentes de otros lugares. Especialmente en el caso de los indígenas, ${ }^{48}$ bajo la amenaza de experimentar dicha novedad desde conductas «de riesgo» (trabajo sexual, drogas, alcohol, etcétera).

En este sentido, cabe resaltar la concepción de la seguridad geográfica endogámica, la cual se aplica al imaginario, desde muchos médicos, sobre las poblaciones indígenas, ${ }^{49} \mathrm{y}$ se replica de forma análoga

\footnotetext{
${ }^{47}$ Estas categorías se cruzan con las mencionadas anteriormente, especialmente en lo referente a la orientación y práctica sexual, dando lugar a variables identificadoras de la probabilidad de ser portador, así como a la mayor o menor exoneración del paciente.

${ }^{48}$ Aquí me refiero a aquellos que viven en sus comunidades de origen y migran a San Cristóbal de Las Casas u otros lugares en México o el extranjero.

${ }^{49}$ Pese a que se pueda admitir la poligamia, la promiscuidad... e incluso se vincule, desde ciertos discursos dominantes, a la violencia y a la idea, racista en este uso generalizador y culpabilizante (por medio de la apelación al argumento de la
}

al concepto de persona autóctona (de San Cristóbal de Las Casas), preservada por un cierto aislamiento geográfico característico (desde esta representación) de la ciudad, ahora amenazada por los riesgos, en este caso relativos a la salud sexual, que implican los extranjeros y sus transgresiones en forma de conductas y referentes nuevos encarnados simbólicamente, en sus cuerpos foráneos alterizados, como una potencialidad portadora de ITS.

Le dije que tuve relaciones con un extranjero. Que estuve con él dos semanas de relación y tuvimos tres veces relaciones... pero que no nos protegimos. Después me enteré de que andaba con otras personas, pero que tenía esa duda de que tal vez me pudo contagiar de alguna enfermedad, por ejemplo el sida que es muy frecuente en muchas personas. Y él (el médico del SAI ) me dijo con tono muy serio: en estas fechas no hay que confiarse porque el sida se extiende por todo el mundo y más si es extranjero. Me sentí regañada incluso por su seriedad. Le dije, bueno, por eso vengo... (Paciente simulada, 28 años, 2012).

Creo interesante problematizar algunas de las consideraciones dominantes con respecto a la concepción del modo de adquisición mayoritario: en este caso la transmisión por vía sexual. Un ejemplo que visibiliza la indefinición de la modalidad de transmisión es el de aquellas personas, portadoras de VIH-sida, que, por ejemplo, han sido transfundidas en una operación y son consideradas población vulnerable y/o con conductas «de riesgo» (entre otras los hombres que tienen sexo con hombres). Frente a la imposibilidad de establecer un criterio diagnóstico en cuanto a la modalidad de la transmisión prevalece, en el médico, un juicio de valor que, en una comparativa de los factores incidentes (no solo de tipo científico sino de tipo valorativo moral) se decantará por aquel factor explicativo que le parezca más sensato en un campo de dos posibilidades: $a$ ) el, supuesto, control actual de la existencia de agentes patógenos en el plasma sanguíneo con el que se realizan las transfusiones y la hipotética, y remota bajo este prisma, posibilidad de adquisición por esta vía. b) Las conductas «de riesgo» de los hombres que tienen sexo con hombres (sexo anal principalmente), y la consideración, entre otras, de una vida sexual muy activa y de una omisión del uso del condón.

cultura, la psicología específica o las condiciones sociales), de depravación, abuso sexual dentro de la familia, maltrato, etc. 
Me pregunto ¿cómo se puede saber el modo de transmisión de, por ejemplo, un hombre a quien han transfundido en una operación (y/o ha consumido drogas inyectables), pero a su vez tiene varias parejas sexuales, mujeres, y asiduamente algún encuentro ocasional con hombres y trabajadoras sexuales? ${ }^{50}$

Pues ahí es más por prejuicios de nuestra parte y de muchos es más bien, porque no solo lo hacen las enfermeras, todo el mundo podría asumir lo mismo pero de asumir... ¿de qué viene?, ¿por qué vienen? Es así, no podría ser de otra manera, incluso hasta muchas veces el prejuicio de que sean por homosexualidad o sea también con hombres y hombres... existe mucho si el señor niega que tuvo relaciones con otras mujeres a que fue a un lugar así, y luego empezamos así «¿y con hombres? No preguntamos ¿Lo operaron? ¿Te hicieron alguna transfusión? ¿Has trabajado? », o sea no, directo (Entrevista médica voluntaria en el consultorio, 2012).

En este sentido, es interesante la reducción etiológica que se establece y la atribución de un patrón de transmisión por vía sexual en función de una serie de características que, desde la representación del médico, denotan un tipo de práctica sexual. En la urgencia de la obtención de información, bajo categorías cognitivas que operan como unidades de conformación de las representación sociales, en función del binomio tiempo/trabajo se resumen las modalidades de transmisión a aquellos marcadores sustentados en una experiencia previa. Dicha experiencia, y sus componentes subjetivos e ideológicos, está reforzada por una ausencia de mecanismos que regulen su exclusión o crítica, en la hegemonía del sentido común desde la que opera (las representaciones/discursos dominantes de la sociedad en la que se inserta) provocando una continuidad «natural» de los mecanismos de validación de los juicios con respecto a la sexualidad del paciente.

El modo de transmisión está circunscrito a los imaginarios dominantes con respecto al sida y a los juicios de valor, como se mencionó, relativos a las prácticas que subyacen en él. Como he podido recoger en los testimonios de algunos médicos y pacientes, y ya se mencionó, se le confiere una mayor importancia al modo de transmisión sexual, el cual trata de ser verificado en la entrevista médica, la exploración y la historia clínica del paciente. Sin embargo, teniendo en cuenta que el consultorio se

\footnotetext{
${ }^{50}$ Para esta discusión véase Pisani (2008).
}

encuentra ubicado en una ciudad en la que el ejercicio y visibilización de las orientaciones y prácticas sexuales disidentes con las heteronormatividad están sancionadas (al existir un fuerte conservadurismo en este sentido), la explicitación de una orientación o práctica homosexual por parte del paciente no siempre es evidente desde la percepción del médico. El juicio por parte del médico, con una intencionalidad diagnóstica y epidemiológica de control y clasificatoria, en algunos casos va de la mano de la desconfianza cuando un paciente (hombre) se define como heterosexual, tiene una mujer e hijos, y sin embargo no acaba de ser, desde su punto de vista, coherente la presentación socio/cultural que escenifica en la consulta. Esto es, la atribución de ciertos rasgos que pudiesen denotar homosexualidad o prácticas sexuales con hombres (por ejemplo, llevar un tipo de jersey, con un color determinado y atado de una forma específica, etcétera).

Un paciente que vestía de forma un tanto peculiar, con una playera bastante pegada al cuerpo, un suéter sobre los hombros cruzado de las mangas bajo el cuello, una cadena de plata grande y gruesa sobre la playera, también llevaba mocasines negros con calcetines blancos, su aseo personal era impecable y su peinado con bastante gel para el cabello, lentes de armazón cuadrado negro grueso, muy de moda actualmente. En general, sin querer encasillarlo en el estereotipo, desde que habló y lo observé con detenimiento me dio la impresión de tener una actitud y tono de voz un tanto «amanerados», por eso cuando mencionó a la esposa y la hija me sorprendí un poco (Entrevista médica voluntaria en el consultorio, 2012).

En lo que aquí interesa dilucidar esta disonancia entre los elementos referentes a la orientación sexual, de heteroadscripción del médico, en función de sus representaciones, y aquellos que, en la narración confesional del paciente, pudiesen ser contradictorios generan desconfianza en el clínico. Lo cual, por lo que he podido observar, conlleva un efecto visible en la información que se proporciona, en una suerte de: «si tú no eres honesto conmigo yo tampoco lo voy a ser contigo» que se traduce en una omisión de la información que el paciente demanda y en un tipo de trato duro y poco condescendiente (percibido por los pacientes reales y simulados entrevistados). Un ejemplo de la omisión de información ha sucedido en algunos casos en los que los pacientes/hombres, algunos con familias, percibidos como homosexua- 
les preguntaban sobre las modalidades de transmisión del VIH y el médico no contestaba o daba alguna respuesta evasiva. Esta suerte de desconfianza opera bajo el prisma, según lo registrado en este caso y en otros análogos en entrevistas y conversaciones informales, de la concepción de una confianza en el médico (casi como un sacerdote) y el castigo, bajo la forma de la evasión a la hora de proporcionar la información que le demandan, con aquellos que no demuestran cuáles son sus conductas y disposiciones... o más bien parecen, desde su percepción, no hacerlo y mantener una presentación socio/cultural «ficticia» de sí mismos. Lo cual me lleva a pensar en dos cuestiones: $a$ ) si no son homosexuales ni tienen sexo con hombres ¿por qué, por ciertas características (disposiciones o prácticas) que el médico les atribuye, deberían inventar aquello que no es para recibir una información y trato adecuado? $b$ ) Si son homosexuales, ${ }^{51}$ o tienen sexo con hombres, y no quieren explicitar dicha práctica u orientación sexual, ¿deberían confesarse y redimirse anunciándolo para tener un trato e información adecuados? Y esto último me lleva a las siguientes cuestiones: ¿deben confiar ciegamente en el médico y en su discreción?, ¿qué justifica, bajo el imperativo de una orientación y atención más adecuadas, la demandada delación de algo que corresponde al derecho a la intimidad del paciente? ${ }^{52}$ Lo cual reenvía nuevamente a la selección social mencionada, sustentada en la autonomización y sobredeterminación de la práctica médica, que no tiene en cuenta, más que bajo el prisma de la relación confesional soteriológica, los condicionantes y violencias que han vulnerado a la persona llevándola a las situaciones de adquisición del VIH-sida. ${ }^{53}$

\footnotetext{
${ }^{51}$ Creo que la percepción de la falta de honestidad con el médico tiene también que ver con una concepción de las identidades y orientaciones sexuales ancladas en el binomio: heterosexualidad/homosexualidad.

52 Esta es una cuestión problemática ya que en la factibilidad de la visibilización-confesión de dichas prácticas sexuales se sustentan dimensiones fundacionales como, entre otras, el tipo de prevención/atención-control del VIH-sida en el consultorio, la posibilidad de recogida de datos epidemiológicos y diseño de estadísticas, el desarrollo de políticas públicas dirigidas a colectivos vulnerables específicos, etc. No obstante, considero que es importante su discusión.

${ }_{53}$ En la mayoría de los pacientes por su condición socio/ económica, género, orientación sexual, etc. En otros casos se ha tratado de accidentes u omisiones del uso de la protección en contextos, por ejemplo, diferenciados de lo que entendemos como susceptibles de vulneración.
}

Un aspecto interesante a la hora de proporcionar información, tanto a este tipo de pacientes, percibidos por ciertos atributos externos de su vestimenta o gestualidad (o algún elemento de su discurso) como homosexuales (o bisexuales) pero que no han declarado abiertamente una orientación o práctica homosexual, como a aquellos que se declaran homosexuales cuando preguntan sobre la posibilidad de tener una familia en el futuro, es el hincapié que hace el médico en un modelo familiar hombre-mujer. La única forma concebida de tener hijos, a juicio del doctor, se inscribe en este modelo familiar en el que hay un padre (hombre) y una madre (mujer), sin «considerar» la posibilidad de adopción en una pareja de hombres. Un elemento de interés, en este sentido, es la falta de capacitación de los médicos en cuestiones de género, diversidad sexual y discriminación, así como la probabilidad de que los estereotipos que tienen acaben reforzándose, en una suerte de profecía autocumplida, ya que subyace la tendencia a generalizar desde una posición social de un campo muy concreto (un consultorio en VIH-sida) relatos de una población muy específica: las personas que viven con VIH-sida, algunas de las cuales tienen trayectorias de vida llenas de dificultades y vulneración. Desde una posición heteronormativa algunas de las narraciones relativas a ciertas prácticas, obviando el componente de exclusión y estigma en las relaciones homoeróticas y/o homosexuales que llevan a que estas personas sean vulnerables, manifiestas o deducidas por el médico pueden acabar confirmando sus supuestos de partida: los homosexuales son todos muy promiscuos, irresponsables, perversos, etc. En este sentido, opera la proximidad a la orientación sexual del médico, ya que el eje divisorio entre anormalidad/normalidad es trazado en función de ella, representante de la norma establecida en la sociedad. Como menciona Gamarnikow (1978), la organización del consultorio reproduce el modelo de familia victoriano hegemónico en la sociedad actual: el médico es el padre, la enfermera la madre y el paciente el hijo. En las entrevistas y conversaciones con los médicos, entre otros en el consultorio del SAI, consideran más irresponsable, perverso y promiscuo tener relaciones o prácticas homosexuales a escondidas con uno o más de un compañero sexual sin protección, que tener relaciones heterosexuales con una o más trabajadoras sexuales, sin protección, y transmitirle el VIH-sida a la 
mujer y los hijos que están por nacer. En el primer caso existe un comportamiento oscuro, desconocido y amenazante, en el segundo se trata de un (desafortunado y, tal vez, irresponsable) accidente.

\section{CÓMO INFLUYE EL ORIGEN ÉTNICO/ CULTURAL DEL PACIENTE EN LAS REPRESENTACIONES Y PRÁCTICAS DEL MÉDICO}

El origen étnico/cultural del paciente influye en ciertas representaciones del médico con respecto al modelo explicativo del proceso salud/enfermedad/ atención y a la sexualidad que atribuye a aquel, así como en algunas de sus prácticas relativas al modo de proporcionar información al paciente y de culparlo o exonerarlo por los problemas en la adherencia al tratamiento ARV. En este sentido, la representación social en cuanto a dicho modelo explicativo suele estar impregnada de una concepción del paciente indígena, adscrito a un conjunto homogéneo (los indígenas vs el mestizo) desde un proceso de minorización (en términos de Py y Jeanneret 1989), como desconocedor de las formas de prevención del VIH-sida y su tratamiento de control por medio de los medicamentos ARV. Los médicos, en el SAI, perciben que los pacientes indígenas tienden a recurrir a los curanderos yerberos, complementando difícilmente medicina alópata y tradicional al desconfiar de la primera y/o creer fervientemente en la segunda, y a concebir que el VIH-sida no existe o es una enfermedad que tiene curación. La cuestión del desconocimiento se articula bajo un esquema que concibe como infantil al paciente indígena por dos motivos: ser paciente e indígena.

Vino un señor de rasgos indígenas, de aproximadamente 38 años, muy sonriente desde la primera vez que lo vi, que incluso se ríe bastante, de lo que sea, incluidos los malos chistes del doctor (como el típico «todavía sigue usted por aquí», haciendo alusión, quiero pensar, al hecho de que no se han muerto). Aparenta de hecho menos edad de la real, por lo mismo de los gestos, más similares a los de un niño. A pesar de eso, al momento de discutir cuestiones sobre su tratamiento se pone muy serio y parece muy consciente y atento de todo lo que el doctor le dice (Entrevista médica voluntaria en el consultorio, 2012).
Por otra parte, se tiene una percepción diferencial en cuanto a la procedencia de los pacientes. En el caso de San Juan Chamula se concibe que son más conflictivos y renuentes a cooperar con la atención médica. Mientras que, por ejemplo, si proceden de Zinacantán se perciben como más colaborativos (esta es una imagen que he podido recoger en diferentes entrevistas con médicos y otros miembros del personal de salud). Se tiende a pensar, tanto los miembros de este consultorio como en otros contextos, que estos pacientes viven en una suerte de seguridad comunitaria autocontenida en la que el riesgo, como una suerte de agente externo amenazante, proviene de su salida al exterior y del contacto con universos y deseos nuevos. La cultura ${ }^{54}$ juega un papel fundamental en el desapego a la consulta por encima de cuestiones relacionadas con la situación socio/ económica y de vulnerabilidad del paciente. Contrariamente a una representación sustentada desde diferentes arenas con respecto a la sexualidad de los pueblos indígenas (discutida en el texto anteriormente) he recogido algunos testimonios, de los médicos y coordinadores que trabajan en el área de la prevención/atención de VIH-sida en los Altos de Chiapas, planteando ciertas hipótesis con respecto a una posible «práctica cultural homosexual» entre hombres en San Juan Chamula. ${ }^{55}$ En este sentido, la idea de una «práctica cultural», como mencionan, interpela a un universo pretendidamente heterosexual y conservador en el cual solo se puede dar la diversidad sexual desde una visión cristalizada en la cultura, entendida como una esencia, que articula y permite la práctica explicando los casos de los hombres que, en el seno de la comunidad, tienen dichas conductas.

San Cristóbal de Las Casas representa, en este sentido, una ciudad que en los últimos años ha vivido grandes cambios y en la que se han instalado nuevos patrones y referentes conviviendo con aquellos ya existentes. La lejanía o cercanía con San Cristóbal también parece ser una variable que incide en las representaciones de los médicos en cuanto a la mayor o menor apertura a ciertas conductas se-

\footnotetext{
${ }^{54}$ Entendida esta, por el médico, como un conjunto de elementos de adscripción y pertenencia del paciente relativos a, entre otras cosas, los valores, lengua, conductas, creencias, normas sociales, etc.

55 Sobre las experiencias homoeróticas en la infancia (que pueden comprender desde juegos, experiencias de coito anal o el abuso sexual), en el ámbito de las comunidades indígenas, ver Núñez (2010).
} 
xuales, especialmente de los jóvenes, así como en el recurso a los médicos alópatas, al atribuir a los pacientes «menos rurales» más conocimiento y acceso a personas que les recomiendan acudir a ellos.

Los mecanismos, mencionados con anterioridad, de culpabilización del paciente, frente a una falla terapéutica, ${ }^{56}$ alegando que no tomó bien sus medicamentos cuando lo que sucedió es que no estaban disponibles, no se dan por igual en aquellos mestizos e indígenas, tal y como he podido constatar en diversos testimonios. La sospecha de la toma desigual de los medicamentos, unida a las representaciones y los estereotipos mencionados anteriormente y a la supuesta menor capacidad de protesta (al encontrarse en una posición subordinada como miembro de un grupo social minoritario), facilita un chivo expiatorio «más accesible» frente a dificultades de otro tipo como son la falta de recursos, o la selección, en su ausencia, entre unos y otros pacientes para su distribución. ${ }^{57}$ Los problemas reales o supuestos, de índole socio/cultural, que tratan de explicar, si no justificar, el hecho de que los pacientes indígenas se apegan menos a la consulta opera bajo la articula-

${ }^{56}$ El concepto de falla terapéutica suele aplicarse a tres escenarios: la falla virológica, inmunológica y clínica. Para más información sobre la falla terapéutica ver Vélez et al. (2005), así como acerca de la falla terapéutica múltiple al tratamiento $A R V$ y los esquemas de rescate me remito a Secretaría de Salud, CENSIDA (2012).

${ }^{57}$ El único laboratorio existente que realiza la prueba de carga viral y CD4 a los pacientes que viven con VIH-sida, pertenecientes a la Secretaría de Salud, en Los Altos de Chiapas se encuentra ubicado en Tuxtla Gutiérrez. Dichos controles, que deben realizarse cada 3-4 meses, son muy útiles para valorar el apego al tratamiento, y la eficacia del mismo, ya que dependiendo de los niveles, virales, identificados se determina si han fallado los medicamentos (fallo terapéutico) y es necesario cambiar a otro esquema o mantener el mismo. A finales del 2011 (entre noviembre y diciembre) se notificó a la consulta una orden de cierre del laboratorio que duró aproximadamente un mes, durante el cual no se pudo enviar a ningún paciente a control. Al momento de la reapertura se notificó una reducción de pruebas de CD4 debido a un recorte presupuestario. Ello implicó que, a partir de entonces, se debían enviar de 20 a 6 pacientes por mes (siendo seis el número estipulado como máximo). La solución, por parte del médico, ha sido tratar de identificar a los pacientes con mayor necesidad de seguimiento para ajustarse al criterio, viéndose obligado a abandonar el protocolo de actuación que exige un control, de este tipo, por paciente cada 3-4 meses. Por otra parte, los medicamentos ARV, correspondientes a ciertos esquemas, no han estado disponibles en alguna ocasión, debido tanto al desabasto como a problemas burocráticos en su administración desde el CAPASIT de Tuxtla, ocasionando que el paciente tuviese que irse sin su tratamiento. ción de un discurso culpabilizador en una suerte de reajuste a dos tiempos: a priori, facilitador de una cita según la confiabilidad supuesta del paciente (va a cumplir con ella), o a posteriori, probablemente fue su irresponsabilidad la falla virológica y si no lo fue la estigmatización étnica ofrece una explicación coherente, para el representante del sistema de cuidados de salud y este en su conjunto, por medio de una forma de violencia simbólica y estructural que invisibiliza su origen (y modalidad operativa, el racismo) para ser más eficaz en su praxis. El culpable aquí no es tanto el individuo y sus conductas sino las colectividades minoritarias que hacen un uso inadecuado de los medicamentos y servicios que se les proporciona (en detrimento de los demás). A este tenor, naturalizando dicha violencia, el mecanismo de autoestigmatización, por el origen étnico, opera en la incorporación de una subordinación interiorizada que, en los campos sociales en los que se asume una alterización como miembro de una minoría en la interacción (como es el de las instituciones de salud), ejerce de explicación hegemónica sobre las conductas y exclusión sufrida. Como menciona una de las pacientes simuladas con respecto a su entrada en la clínica: «Esta vez me trataron bien porque iba vestida con mi ropa buena, no con la de Chamula (como en otras ocasiones). Creo que fue por eso» (paciente simulada, 28 años, 2012).

Según he podido recoger en los diversos testimonios de médicos y pacientes (que acuden al consultorio del SAI) el tipo de información y el modo de transmitirla se selecciona en función del origen del paciente tras evaluar si va a entender, mejor o peor, el español, así como a compartir o no los mismos, o semejantes, modelos explicativos del proceso salud/enfermedad/atención capitalizando los términos médicos relativos al diagnóstico, seguimiento y control de la enfermedad. En el caso de los pacientes indígenas o bien el médico explica técnicamente, de la misma manera que con los no indígenas hispanohablantes, sin realizar un esfuerzo para traducir lingüística y/o culturalmente términos relativos a, por ejemplo, el virus de la inmunodeficiencia adquirida, el examen de carga viral o de CD4, o la explicación es más escueta. En este sentido, un médico que trabaja en el área de la atención a personas con VIH-sida en la región me comentaba que él y muchos de sus compañeros (refiriéndose, a su vez, a la Clínica I objeto de estudio) en ocasiones, inconscientemente, 
no ofrecen las mismas explicaciones a los pacientes indígenas que a los mestizos. Esto tenía que ver, en su opinión, con la frustración de percibir cómo realizan un esfuerzo infructuoso por hacerse entender, traduciendo términos. Añadía que la presión frente al fracaso los lleva a desistir y se produce una criba importante en el tipo de explicación que se da, ya que, al igual que les sucede a sus compañeros, piensa que los pacientes indígenas no van a entenderle y esto, unido a otros condicionantes socio/culturales, conllevará tarde o temprano a un desapego a la consulta y el tratamiento. Lo cual, como una suerte de profecía autocumplida, ciertamente termina sucediendo. El siguiente ejemplo da cuenta de la articulación de la selección del tipo y el modo en el que se ofrece la información, por parte del médico, a la luz de uno de los argumentos que los facultativos suelen utilizar para explicar el desapego especialmente en pacientes indígenas. Los pacientes indígenas no conocen qué es el VIH-sida y piensan que, al igual que otras enfermedades, tiene cura. Al ser asintomático, en algunos de sus estadios, no son partidarios de tomar la medicación y cuando lo hacen sus efectos secundarios, durante el primer mes (o los primeros meses), los llevan a desistir ya que, por su desconocimiento, sienten que empeoran (cuando antes de la medicación no percibían malestar alguno). «El primer mes de tratamiento tiene más efectos que antes y por eso piensa [el paciente] que no le va a servir, ya que tiene diarreas, náuseas, ictericia... y el paciente quiere sentirse mejor a corto plazo. Un paciente indígena se asusta [...] La población indígena abandona rápido si ve que no existe una mejoría en un mes» (Médico en el consultorio del SAI, 2012).

Los médicos, según me relatan, no les explican, en la mayoría de los casos, cuáles pueden ser los efectos secundarios de los ARV. ${ }^{58}$ Frente a la pregunta que le hice a la médica voluntaria en el SAI acerca de si me ofrecería a mí información, en el caso de necesitarla si viviera con VIH-sida y comenzase con el tratamiento ARV, sobre los posibles efectos secundarios de dichos medicamentos me comenta que, obviamente, a mí sí me la ofrecería:

${ }^{58}$ El médico y el resto del personal de salud deben informar escrupulosa y claramente a los pacientes acerca de la infección del VIH, así como de las metas y potenciales efectos adversos de los antirretrovirales. Esto facilita el diagnóstico oportuno de complicaciones relacionadas con los medicamentos, optimiza la tolerancia y adherencia al tratamiento a largo plazo (Brodt 1997, citado en CENSIDA 2012b).
Es que ahí se trata diferente porque si tuviera que decírtelo a ti: «mira, tienes VIH y tienes que tomarte estos y estos medicamentos, están estos, causan esto... y estos no se sabe, entonces está de ti si los tomas»... entonces sí te daría todo la información probablemente [...] yo con un señor que no está muy convencido de nada de entrada no le voy a dar toda esa información, «mire, señor, estos son los medicamentos que le pueden salvar la vida, que le pueden prolongar» y eso creo que sería más en lo que me enfocaría y tal vez que «al principio le puede dar diarrea» $\mathrm{y}$ «al principio se le puede caer el pelo». Pero me enfocaría más en que lo haga por favor, porque yo realmente he visto y alguna vez un paciente me preguntó que si yo creía que servían más estas medicinas que las plantas y yo le dije que por mi experiencia y mi formación en este tipo de enfermedades yo no le apostaría a las plantitas (Entrevista médica voluntaria en el consultorio, 2012).

La traducción/interpretación lingüística/cultural que debe o debiera realizar el médico (más aún en ausencia de un traductor profesional adscrito a la consulta), abarca cuestiones relativas a la lengua no compartida y a la traducción de los términos médicos a aquellos que, de ser el caso, maneja el paciente y difieren de estos, así como otros elementos socioculturales que intervienen en el proceso salud/enfermedad/atención y/o comprometen la adherencia a la consulta y al tratamiento ARV. Un ejemplo de ello es la importancia de una explicación comprensible de los efectos secundarios del medicamento al estar articulada con «ciertos elementos culturales» ${ }^{59}$ que intervienen en la farmacodinamia del medicamento. Este es el caso de la posible ingesta de alcohol por parte del paciente y las contraindicaciones que pueda tener con los medicamentos ARV. Un paciente originario de una comunidad aledaña a San Cristóbal de Las Casas me mencionaba que le daba miedo el posible efecto venenoso del alcohol y los medicamentos. Su preocupación principal residía en el hecho de tener que desempeñar un cargo en su comunidad que implicaba beber ocasionalmente pox, dos o tres veces al mes, en ciertos actos y ceremonias. Pese a confiar en la eficacia del tratamiento ARV y desear tomarlo esta era la razón por la que dudaba si comenzar o no a utilizarlos. Al preguntar sobre ello, explica, no le supieron contestar en la clínica de la cabecera municipal ni en el SAI, de la clínica

\footnotetext{
${ }^{59}$ La explicación biomédica también es cultural. Aquí me refiero a aquellos, externos al ámbito del consultorio médico, en la vida del paciente.
} 
I, y se quedó con la duda. El epidemiólogo que me acompañó a la entrevista le estuvo explicando que no se convertía en veneno, sino que el efecto del medicamento se neutralizaba con la ingesta de alcohol, pero que lo importante sería que lo tomara todos los días y, le sugirió, que preguntase en el consultorio del SAI acerca de ello en función de las veces que iba a consumir alcohol. Esta entrevista, al igual que otras, tuvo la característica de ser una capacitación sobre las dudas que tenía el entrevistado acerca del VIH-sida, su transmisión y su atención/control médico. El paciente nos preguntó si había medicamentos que pudieran curar la enfermedad (refiriéndose, posteriormente, a si en España, mi país natal, eran mejores que en México), ${ }^{60}$ así como si el VIH-sida existía en otras partes del mundo y en qué proporción. A su vez dudaba de si podía tomar vitaminas y remedios de medicina tradicional, a base de plantas, a la par que los medicamentos ARV. Una discusión que se ha planteado en las entrevistas con varios pacientes es el recurso a los iloles, y a los remedios terapéuticos de la fitoterapia, para la cura del VIH-sida. La discusión entre medicina tradicional y medicina alopática suele ser percibida por los médicos que he podido entrevistar como una confrontación que perjudica la adherencia al tratamiento con medicamentos ARV. En el caso del VIH-sida, al ser una enfermedad crónica y asintomática en ciertos estadios, la percepción de la eficacia del tratamiento es problemática y guarda, si cabe, una mayor relación casi con un acto de fe que en las enfermedades en las que se puede constatar la curación y atribuirla al tratamiento.

A este tenor, la concepción del pluralismo asistencial y de las trayectorias de búsqueda de atención que tienen algunos de estos médicos, con respecto a los pacientes indígenas, es que el recurso a los curadores tradicionales, y otras terapias alternativas a la biomédica, es el primero utilizado, por razones culturales (bajo este nombre apelan a la mayor creencia, fundada en la ignorancia y el desconocimiento, en sus efectos curativos, principalmente), para luego, tras la constatación de su fracaso, acudir a la biomedicina. En el caso de recurrir a ello mientras toman el tratamiento ARV suelen abandonarlo por incompatibilidad entre ambos: «los pacientes indígenas acuden generalmente a los brujos [...] escu-

\footnotetext{
${ }^{60}$ Lo cual me ha sucedido en otras ocasiones, con respecto a aspectos como la actualización de conocimientos respecto al VIH-sida, también con médicos.
}

ché el caso de uno que incluso dice que cura el sida [...] Existen un tipo de terapias con imanes a la que acuden, entre otras terapias alternativas. En un caso de un paciente le dijeron que le iban a curar y que suspendiese el tratamiento, biomédico, ya que podía matarlo» (Médico en el consultorio del SAI, 2012).

Dicha representación instaura una marcada diferencia con respecto a los pacientes mestizos quienes, desde su punto de vista, acudirán a otras modalidades de atención, o recurren a la autoatención de forma, por lo general, incluyente (por ejemplo, pueden tomar los medicamentos ARV y acudir a ritos de sanación en su iglesia, al mismo tiempo...), ya que tratarán de hacer frente a la enfermedad, como sujetos conocedores, con todos los recursos posibles. La no exclusión y la apertura, cuando existe una información y una mediación efectiva, entre los recursos terapéuticos de ambos universos de cuidados ha sido manifestada, en las entrevistas y charlas informales, por varios pacientes indígenas. Sin embargo, una variable en este sentido que parece incidir es que sucede, mayoritariamente, con personas que se encuentran en fase no asintomática de la enfermedad.

En un caso en particular en el que acudimos a visitar a un paciente (adolescente) que, según le habían comentado los médicos de la comunidad al epidemiólogo, no quería tomar el medicamento ARV, la madre (acompañada de la promotora de salud) nos mencionaba que tomaba remedios a base de plantas para la enfermedad (el VIH-sida), y los medicamentos contra la tuberculosis suministrados por la clínica. Un yerbero de San Cristóbal le proporcionaba el medicamento, el cual era traído desde Comitán. Me sorprendió el hecho de que tomase los medicamentos antituberculosos junto con el tratamiento derivado de la fitoterapia para el VIH, y sin embargo no pudiera compatibilizarlo con los ARV. Tuvimos una discusión acerca de la incompatibilidad de los medicamentos con las hierbas en la cual la madre comentaba que no se podían, según el yerbero, tomar mientras se utilizaba este remedio, que duraría aproximadamente tres semanas (ya había tomado el primer ciclo, pero le quedaba el segundo y último). Ante la negativa a comenzar inmediatamente el tratamiento ARV tratamos de negociar los tiempos, el enfermero que nos acompaña (de la clínica de San Juan Chamula) proponía que viéramos los efectos de las hierbas y si no sirvieran se tomaría los ARV. Sin embargo, el epidemiólogo comentó que «desde 
el punto de vista médico y teniendo en cuenta su precario estado de salud (no puede casi levantarse de la cama), tres semanas son demasiado». Comienzo a sentir la impotencia que imagino, según me han relatado, sienten muchos profesionales de la salud al recibir negativas frente al tratamiento que proponen y perciben como la única solución para evitar un desenlace fatal y tratar de curar o controlar la enfermedad. Tengo ganas de decirles (a la madre y al paciente) que «los medicamentos ARV son la única forma de que se salve y que la hierbas no van a hacer nada», no obstante, pensándolo dos veces, opto por comentar que «yo había escuchado también lo de la incompatibilidad de los medicamentos y las hierbas, sin embargo (pregunto) creo que es solo con las inyecciones». La madre contesta que «así es». Continúo mencionando que «los medicamentos ARV son pastillas, al igual que los antituberculosos», y les propongo entonces, en forma de pregunta, que «¿por qué en lugar de esperar a ver el efecto que tengan las hierbas, con el riesgo que podemos correr en la espera, no se toma las dos cosas a la vez: los ARV y las hierbas?» De esta forma, explico, «podemos juntar los efectos beneficiosos de ambas cosas para controlar la enfermedad de su hijo y tratar de que se ponga lo más sano posible». A partir de esto, y del debate en esta dirección que suscita, la madre cambia completamente de actitud (receptiva pero algo recelosa, según mi interpretación) a una apertura a nuestras propuestas y requerimientos acudiendo con gran solicitud a proporcionarnos los papeles que se necesitan para dar de alta al paciente en el SALVAR, y trata de encontrar una solución, con el epidemiólogo, al problema de ser un menor de edad y no poder acudir solo a los exámenes de CD4 y carga viral en Tuxtla.

La mención a los remedios de la fitoterapia suele ser un elemento discursivo recurrente en el caso de algunos pacientes indígenas. Los médicos, en este ámbito y contexto de estudio, con cierta angustia adaptativa, suelen atribuir parte de la falta de adherencia (a la consulta) a los curanderos que prometen curar el sida y a la errónea creencia en ellos y sus remedios. Bajo este argumento se obvia la posible existencia y compatibilidad de modelos explicativos del paciente, y la reacción negativamente del médico frente a la mención a estos remedios. La mención, a mi parecer, en muchas ocasiones no es un ataque contra la eficacia y funcionalidad de los
ARV sino que constituye un recurso familiar al universo del paciente escenificado desde una presentación cultural que trata de ser verídica. Esto es, muchos pacientes creen en los medicamentos ARV, sin embargo, hablan de las plantas ya que, además de dudar en algunos casos si pueden curar o no, ponen sus esperanzas en cualquier remedio, sea cual sea, que les permita vivir y esté articulado a uno de sus sistemas de creencias. Dicho sistema puede emerger discursivamente en el escenario del universo biomédico de cuidados en forma de preguntas sustentadas en experiencias, o narraciones de experiencias anteriores que se materialicen, desde su alterización como «otro» en la relación de multiculturalidad significativa y de poder asimétrico médico/paciente, como información no solo sobre lo que se cree y se explicita ser, sino sobre lo que los otros creen que se es y se debe ser. $\mathrm{Y}$ esto pretende, o confirma, una interacción verosímil desde el punto de vista, en este caso, de las identidades y su producción y reafirmación al constatar la diferencia, mediada por las disposiciones en juego y las relaciones de poder, en el encuentro médico/paciente. Por otra parte, la cristalización del médico de este recurso como el enemigo significado, fruto del miedo y la lucha por la legitimidad del saber en un contexto donde hay que actuar con urgencia (para que el paciente no desaparezca de la red de cuidados), lleva a obviar otras razones, que no guardan relación con un rechazo a los médicos alópatas, por las que el paciente decide acudir a los yerberos y excluir en algunos casos a la biomedicina. El desconocimiento de sus derechos a ser atendidos, así como de la cultura organizativa de cuidados y la forma de acceso a la atención (trámites, tiempos, procesos, etc.), la discriminación (por parte del personal de cuidados en la cadena hasta llegar al SAI), el costo económico y tiempo del desplazamiento, entre otros factores, son obviados por el médico bajo el argumento de una concepción excluyente, medicina alopática vs medicina tradicional, de los cuidados. ${ }^{61}$

\footnotetext{
${ }^{61}$ Apelar al desconocimiento, a la intolerancia o a la mayor confianza en la medicina tradicional, no biomédica, de colectivos socio/culturales minoritarios para justificar los mecanismos de exclusión a los cuidados institucionales de salud es un recurso, desafortunadamente, recurrente en diversos contextos y países (véase Muñoz 2013).
} 


\section{CONSIDERACIONES FINALES}

En el presente texto se han abordado ciertas problemáticas en el acceso, por parte de los usuarios, a la prevención/atención/control del VIH-sida del consultorio médico del Servicio de Atención Integral (SAI) de la clínica I, perteneciente al segundo nivel de atención de la Secretaria de Salud, de San Cristóbal de Las Casas. Algunas de ellas, por medio de las representaciones sociales y prácticas profesionales del médico, tienen que ver con dos variables, entrecruzadas pero que analíticamente diferencio, que vinculan criterios de clasificación social/ideológica y clínica/ técnica del paciente: por una parte, las concepciones estigmatizadoras del vector de transmisión del VIH-sida y de la orientación y las prácticas sexuales del paciente (articuladas a su género, su procedencia autóctona o alóctona y su trayectoria sociocultural) y la consideración de su mayor o menor carácter fidedigno, en la interacción médico/paciente, desde el punto de vista del refuerzo de las representaciones previas que el médico posee con respecto a su orientación sexual. Lo cual reenvía a una selección social, sustentada en la autonomización de la práctica médica, que no tiene en cuenta, más que bajo el prisma de la relación confesional soteriológica, los condicionantes y violencias que han vulnerado a la persona llevándola a las situaciones de adquisición del VIH-sida.

Y por otra, con el origen étnico/cultural del paciente y su modelo explicativo del proceso salud/ enfermedad/atención y sexualidad, se reproduce, a través de la sobredeterminación cultural, una subordinación de los sujetos alterizados por su adscripción étnica. Las concepciones desvalorizantes del paciente indígena (ignorancia, infantilismo, desconfianza hacia el modelo biomédico de cuidados y sus profesionales, etc.) articuladas por medio de un discurso que culpabiliza (los indígenas se apegan menos a la consulta que los mestizos por razones de tipo cultural) permiten a la institución, a través del médico, dirimir problemas como la falta de recursos (pruebas CD4 y carga viral o medicamentos ARV), reproduciendo un universo de cuidados destinado a la población mestiza heterosexual, a través de una selección social sustentada en la mayor o menor cercanía entre el itinerario sociocultural del paciente y el del médico. De forma análoga sucede con la selección del tipo de información que el médico proporciona estructurada en torno a dicha variable étnica/cultural y a los supuestos sobre si va a entender, mejor o peor, el español el paciente, así como a compartir o no los mismos, o semejantes, modelos explicativos del proceso salud/enfermedad/atención capitalizando los términos médicos relativos al diagnóstico, seguimiento y control de la enfermedad.

El hecho de que una sola persona se encargue del consultorio médico del SAI no facilita la actividad reflexiva, y/o retroalimentación, con respecto a su práctica profesional. Es cuestionable, a su vez, la «operatividad» de una consulta que pretenda ser eficaz, en un contexto de diversidad lingüística y cultural, cuando el médico solo puede prestar la atención en español. Estos factores, entre otros, y el confinamiento espacial del médico que condiciona el conocimiento de los pacientes, y sus contextos de vida, al único referente de lo que se escenifica e interpreta en la consulta refuerzan sus mencionadas representaciones sociales sustentadas en la cotidianidad de su experiencia profesional en el SAI. Por otra parte, la centralización de los medicamentos y pruebas CD4 y carga viral en Tuxtla Gutiérrez, y su ocasional desabasto, no ayudan en la adherencia de los pacientes al tratamiento ARV.

Una propuesta, al tenor de las dimensiones analizadas, que permitiría mejorar algunos de los aspectos que tienen que ver con la incidencia de los supuestos morales e ideológicos del médico, articulados en el campo de prácticas del consultorio y sus condiciones estructurales, es el mayor seguimiento institucional por medio de evaluaciones y monitoreos del servicio y de las capacitaciones, así como una formación efectiva, y obligatoria, en cuestiones de género, disidencia sexual, discriminación, derechos humanos y atención sanitaria en la diversidad cultural. Sería importante el desarrollo y la implementación de un modelo de atención médica intercultural que incluya en la consulta a traductores lingüístico/culturales, profesionales, así como estrategias de mediación entre los modelos explicativos del proceso salud/enfermedad/atención del terapeuta y los pacientes, en ocasiones diversos y no coincidentes.

La promoción, y dotación de recursos para su viabilidad, de una concepción de la praxis médica que comprenda las variables socioculturales, además de las biológicas, del proceso salud/enfermedad/atención a través, en este caso, de la ruptura con el confinamiento espacial del médico y su acercamiento a 
los contextos de vida de los pacientes coadyuvaría en la lucha contra la mencionada selección social, por medio de la discriminación, que se lleva a cabo en el consultorio.

Por otro lado, creo que es fundamental la participación de los pacientes y la sociedad civil en el funcionamiento y la supervisión del servicio de salud a la hora de enfrentar algunas de las problemáticas, en la relación médico-paciente-institución, mencionadas. Para ello sería pertinente el impulso de un grupo de autoapoyo en el SAI que permita, generando espacios y momentos de encuentro entre los pacientes, dar respuesta a algunas de sus demandas, por ejemplo, consejos sobre los problemas relativos a la discriminación (o el curso del padecimiento) desde aquellos con más experiencia a los recién diagnosticados, y fortalecer sus habilidades en términos de agencia individual y colectiva. Y, a su vez, involucrar a la sociedad civil a través de iniciativas cuyas actividades comprendan la lucha contra la discriminación de las personas que viven con VIH-sida por medio de la sensibilización del personal de salud, del SAI, y el monitoreo y la rendición de cuentas de sus servicios. Todo ello redundaría en la mejora de la calidad de la atención médica implicando un refuerzo de la adherencia a la consulta, especialmente en los pacientes que por su trayectoria sociocultural sufren discriminación.

\section{FUENTES DE CONSULTA}

Abric, Jean Claude, 2001, «Metodología de recolección de las representaciones sociales», en Prácticas sociales y representaciones J. C. Abric (coord..), Ediciones Coyoacán, México, pp. 53-74.

Álvarez, Julio Félix y Guadalupe del Carmen Álvarez, 2011, «Las percepciones sobre la práctica médica en la región fronteriza de Chiapas», $A n$ damios. Revista de investigación social, v. 8., n. 16, pp. 287-321.

Arguello, Hilda y Graciela Freyermuth, 2004, «Servicios de atención gineco-obstétrica hospitalaria: descripción y análisis», en: sureste.ciesas. edu.mx/Investigacion/Proyectos\%20especiales/Proyectos/Graciela/Hospitales.pdf [consulta: 23 de enero de 2012].

Balandrán, Dulce, Juan Gutiérrez y Martín Romero, 2011, «Evaluación de la adherencia antirretro- viral en México. Índice de adherencia vs adherencia de cuatro días», XII Congreso Nacional sobre VIH-sida, Villahermosa.

Castañeda, Xochitl, Emperatriz Delgado, Nora Brie, Elizabeth Cancino, Raquel Castañeda y Martín De la Cruz, 1997, «Adolescencia, género y sida en áreas rurales de Chiapas», en Género y salud en el suroeste de México, E. Tuñón (coord.), El Colegio de la Frontera Sur/Universidad Juárez Autónoma de Tabasco, Chiapas-Tabasco, pp. 55-83.

Castro, Arachu, 2005, «Adherence to Antiretroviral Therapy: Merging the Clinical and Social Course of AIDS», Plosmedicine, v. 2, n. 12, p. 1217-1221.

CENSIDA, 2009a, «El VIH/sida en México 2009», en: www.censida.salud.gob.mx/descargas/2009/ VIHSIDAenMexico2009.pdf [consulta: 14 de abril de 2011]. 2009b, «25 años de sida en México. Logros, desafíos y retos», en: www.censida. salud.gob. $\mathrm{mx} /$ descargas/SIDA25axos-26mar.pdf [consulta: 3 de abril de 2011].

__, 2012a, «Vigilancia epidemiológica de casos de VIH/sida en México. Registro nacional de casos de sida. Actualización al 30 de junio de 2012», en: www.censida. salud.gob.mx/descargas/2012/sida_vih30junio2012pub2.pdf [consulta: 12 de diciembre de 2012].

__, 2012b, «VIH/sida en México 2012», en: www. censida.salud.gob.mx/descargas/biblioteca/VIHSIDA_MEX2012.pdf [Consulta: 20 de enero de 2013]

CENSIDA, Instituto Nacional de Salud Pública (INSP) y Secretaría de Salud, 2009, «VIH/sida y salud pública. Manual para personal de salud», en: www.censida.salud.gob. mx/descargas/biblioteca/ manualvihsidaysaludpub.pdf [consulta: 10 de junio de 2011]

Comaroff, Jean, 2007, «Beyond Bare Life: AIDS, (Bio)Politics, and the Neoliberal Order», $\mathrm{Pu}$ blic Culture Winter, v. 19, n 1, pp. 197-219.

Evangelista, Angélica y Edith Kauffer, 2007, «Jóvenes y VIH/SIDA. Contextos de vulnerabilidad en comunidades rurales de la región fronteriza de Chiapas», en Compartiendo saberes sobre el VIH/sida en Chiapas, R. Tinoco, M. E. Martínez y A. Evangelista (coords.), Instituto de Salud del Estado de Chiapas/Centro de Inves- 
tigaciones en Salud de Comitán/Consejo Estatal de Población/El Colegio de la Frontera Sur, Chiapas, pp. 77-98.

Farmer, Paul, 1992, Haiti and the geography of blame: AIDS and acusation, University of California Press, Berkeley.

Fassin, Didier, 2000, Les Enjeux politiques de la santé. Études sénégalaises, équatoriennes et françaises, Karthala, Paris.

Fernández-Rufete, José, 2000, «El afecto perdido», en Medicina y cultura. Estudios entre la antropología y la medicina editado por Perdiguero, Enrique y Josep Comelles, Bellaterra, Barcelona, pp. 277-304.

Festinger, Leon, Henry Riecken y Stanley Schachter, 1970, When Prophecy Fails, a social and psychological study of a modern group that predicted the destruction of the world, University of Minnesota, Minneapolis.

Freyermuth, Graciela, 2007, «Migración y enfermedades de transmisión sexual en Chamula, Chiapas. Un estudio exploratorio (1 ra. parte)», en $E$ l señuelo del Norte. Migración indígena contemporánea, San Cristóbal de las Casas, Chiapas, coordinado por Freyermuth, Graciela, Sergio Meneses y Germán Martínez, COESPO, Fondo de Población de las Naciones Unidas, ACAS, Chiapas, pp. 61-98.

Gamarnikow, Eva, 1978, «Sexual division of labour: the case of nursing», en Feminism and Materialism, editado por Kuhn, A. y A. Wolpe, Routledge and Kegan Paul, Londres, pp. 96-123.

Gobierno del Estado de Chiapas, 2012, «Boletín 8735», en: www.chiapas.gob.mx/prensa/ boletin/fortalecen-atencion-para-la-mujer-en-zona-altos [consulta: 23 de enero de 2013].

Goffman, Erving, 2006 (1963), «Estigma: la identidad deteriorada», Amorrortu, Buenos Aires.

Infante, Cesar, Ángel Zarco, Silvia Magali, Ken Morrison, Marta Caballero, Mario Bronfman y Carlos Magis, 2006, «El estigma asociado al $\mathrm{VIH} /$ sida: el caso de los prestadores de servicios de salud en México», Salud Pública de México, v. 48, n. 2, pp. 141-150.

Infante, César, Peter Aggleton, Pat Pridmore, 2009, «Forms and Determinants of Migration and HIV/AIDS. Related Stigma on the Mexican-Guatemalan Border», Qualitative Health Research, v. 19, n. 12, pp. 1656-1668.
Instituto Nacional de Estadística y Geografía (INEGI), 2005, «Conteo de población y vivienda 2005», en: www.inegi.org.mx/sistemas/olap/proyectos/bd/consulta.asp?p=10215\&c=16851\&s=est [consulta: 16 de marzo de 2011].

Leyva, René y Frida Quintino, 2007, Diseño, implementación y evaluación de un sistema de atención integral de VIH/sida en poblaciones móviles y migrantes en la frontera MéxicoGuatemala. Informe Técnico Final, Instituto Nacional de Salud Pública, Cuernavaca.

Macías, Eric, 2012, «Reconstruyendo y relacionando las experiencia de migrar y enfermar. Representaciones sociales y trayectorias de búsqueda de atención en personas que viven con VIH con experiencias de migración en el CAPASITS de Poza Rica, Veracruz», tesis de maestría, CIESAS, México.

Menéndez, Eduardo, 2006, «Interculturalidad, diferencias y antropología at home. Algunas cuestiones metodológicas», en Salud e inteculturalidad en América Latina coordinado por Fernández Juárez, Gerardo, Abya Yala, Quito, pp. 51-66.

Menéndez, Eduardo, 2009, De sujetos, saberes y estructuras: introducción al enfoque relacional en el estudio de la salud colectiva, Lugar Editorial, Buenos Aires.

Moscovici, Serge, 1979, El psicoanálisis, su imagen y su público, Huemul SA, Buenos Aires.

Muñoz, Rubén, 2013, «Mediación intercultural frente a la desigualdad en el acceso y disfrute a la atención sanitaria. Algunas propuestas y problemáticas de sus praxis en Bélgica y España», Revista Migraciones, n. 33, pp. 97-125.

Núñez, Guillermo, 2010, Vidas vulnerables. Hombres indígenas, diversidad sexual y VIH-sida, Edamex/CIAD, México.

Organización Mundial de la Salud (OMS), 2004, «Adherencia a los tratamientos a largo plazo. Pruebas para la acción», en: www.paho.org/ spanish/ad/dpc/nc/adherencia-largo-plazo.pdf [consulta: 15 de mayo de 2011].

Pisani, Elizabeth, 2008, La sabiduría de las putas. Burócratas, burdeles y el negocio del sida, Sexto Piso, México.

Ponce, Patricia, 2011, «Pueblos indios y VIH/sida: Nuevas miradas epidemiológicas, socioculturales y políticas públicas», en El VIH y los pue- 
blos indígenas, P. Ponce, R. Hernández, J. Torres y A. Rascón (coords.), Comisión Nacional de los Derechos Humanos, México, pp. 7-23.

Reartes, Diana, 2010, «Movilidad territorial y construcción de vulnerabilidad frente a ITS/VIH/ sida entre estudiantes indígenas de Chiapas», Miradas en movimiento, v. 4, pp. 70-95.

Robledo, Gabriela, 2009, Identidades femeninas en transformación: religión y género entre la población indígena urbana en el altiplano chiapaneco, CIESAS, México. (Publicaciones de La Casa Chata).

Rosenhan, David, 1973, «On being sane in insane places», Science, v. 179, pp. 250-258.

Secretaría de Salud, CENSIDA, 2006, «Manual de organización específico del Centro Ambulatorio para la Prevención y Atención del sida y otras Infecciones de Transmisión Sexual», en: www. censida.salud.gob.mx/descargas/man_org_capasits.pdf [consulta: 10 de junio de 2011].

Secretaría de Salud, CENSIDA, 2012, «Guía de manejo antirretroviral de las personas con VIH-sida», en: www.salud.gob.mx/conasida [consulta: 5 de septiembre de 2011].

Truzzi, Marcelo, 1974, «Towards a Sociology of the Occult: Notes on Modern Witchcraft», en I.
Zaretsky y L. Mark Leone (coodrs.), Religious Movements in Contemporary America, Princeton University Press, Princeton, pp. 628-645.

Turner, Bryan, 1987, Medical power and social knowledge, Sage publications, Nueva York.

Vélez, Hernán, William Rojas, Jaime Borrero y Jorge Restrepo, 2005, Fundamentos de medicina. Manual de VIH/sida y otras Infecciones de Transmisión Sexual, Quebecor World, Bogotá.

Wallis, Roy, 1976, The Road to Total Freedom, a Sociological Analysis of Scientology, Heinemann, Londres.

Wallraff, Gunter, 1994 (1987), Cabeza de turco, Anagrama, Barcelona.

\section{ENTREVISTAS}

Médico del SAI, 2011

Médica voluntaria en el consultorio del SAI, 2012

Paciente simulada, 28 años, 2012

Responsable del programa de VIH-sida en Los Altos de Chiapas, 2012

Fecha de recepción: 5 de septiembre de 2013. Fecha de aceptación: 25 de octubre de 2013. 